\title{
Measuring the Effects of Zen Training on Quality of Life and Mental Health Among Japanese Monk Trainees: A Cross-Sectional Study
}

\author{
Fumio Shaku, MD, Madoka Tsutsumi, MA, Hideyoshi Goto, MA, ${ }^{2}$ and Denise Saint Arnoult, $\mathrm{PhD}^{3}$
}

\begin{abstract}
Objective: Previous studies have reported that the practice of meditation can have beneficial physiologic and mental effects. Therefore, Zen trainees who regularly practice meditation might have high quality-of-life scores and high levels of general mental health; however, no previous study has tested these relationships. This article reports on a study that examined how rigorous professional training affected the International Quality of Life (QOL) Assessment Short Form-36 (SF-36) and General Health Questionnaire-28 (GHQ-28) scores of Zen trainees in Japanese monasteries.

Design: This was a single-center questionnaire-based study.

Settings/location: The study was conducted in Rinzai Zen monasteries.

Subject interventions: Anonymous and confidential surveys containing the SF-36 and GHQ-28 were distributed by mail, and 256 questionnaires were collected from Rinzai Zen monasteries.

Outcome measures: One hundred ninety-eight complete questionnaires were collected and the participants were divided according to their training length: group I ( $<1$ year), group II (1-3 years), and group III ( $\geq 3$ years). Oneway analysis of variance and Tukey test for multiple comparison were conducted on normally distributed data, and the Kruskal-Wallis test was performed on non-normally distributed data.

Results: The SF-36 seven subscale scores (physical functioning, role-physical, body pain, general health, vitality, role-emotional, and mental health) of the longer-length training group were significantly higher compared to other groups. The SF-36 MCS (mental component summary) score among the groups were significantly different, and the scores of group III were significantly higher compared to the scores of group I. Furthermore, the GHQ-28 total and subscales (somatization, anxiety, social dysfunction, and depression) scores of longer-length training were significantly lower (better).

Conclusions: These findings suggest that Zen professional training, including inward-attention practices, improves the QOL and general mental health of trainees, even in a tough and distressing environment. However, detailed qualitative and longitudinal studies are required to fully assess these effects.
\end{abstract}

\section{Introduction}

$\mathbf{M}$ INDFULNESS IS WIDELY KNOWN and used to improve psychologic condition. Mindfulness-based stress reduction (MBSR) was founded in 1979 by Dr. Jon Kabat-Zinn ${ }^{1}$ as a way to enhance a patient's functional abilities and improve overall well-being by reducing painful physical symptoms and psychologic distress. ${ }^{2}$ This practice was designed to teach patients with chronic medical conditions how to live fuller and healthier lives. ${ }^{1}$ Numerous studies have shown that meditation affects certain physiologic and mental functions. ${ }^{1,3-10}$ For example, stress reduction programs that employ mindfulness meditation training can reduce psychologic symptoms, increase patients' ability to exert control over specific domains of their lives, and, consequently, lead to higher scores on measures of patients' spiritual experiences. ${ }^{11}$

Scientific and scholarly interest in MBSR has grown over the last 2 decades. Studies have examined the effectiveness of MBSR in diverse populations, including health care providers and individuals diagnosed with cancer, depression, and heart disease. For example, researchers found significant reductions in depression and anxiety scores (as measured by

\footnotetext{
${ }^{1}$ Department of General Medicine, University of Tsukuba, Tsukuba, Ibaraki, Japan.

${ }^{2}$ Sakura Clinic, Iwate, Japan.

${ }^{3}$ Division of Acute, Critical, and Long-Term Care (Div. I), University of Michigan School of Nursing, Ann Arbor, MI.
} 
the Beck Depression Inventory, Spielberger State-Trait Anxiety Inventory, and Dysfunctional Attitude Scale) among members of an intervention group such as chronically ill members of an intervention group and their health care providers, whose interactions with the patients were enhanced after completing an MBSR program. ${ }^{12}$

The history of MBSR begins with the traditional mindfulness meditation techniques practiced in Indian Theravada and Mahayana Buddhism approximately 2500 years ago. Zen meditation is one of the core practices in Buddhism. This Buddhist meditative exercise has its roots in the metaphysical tenet of "emptiness," which stems from the writings and beliefs of the Japanese Zen schools. ${ }^{13}$ The practice of Zen meditation has been described in detail in several previous studies and works. ${ }^{14,15}$ Harmony of and balance between body, breath, and mind are essential ingredients in the practice of Zen. ${ }^{16}$ Cardiorespiratory interactions have been investigated among the physical functions in the practice of Zen. For example, Zen meditation synchronizes cardiorespiratory interaction with respect to breathing oscillations and the heart rate variability induced by respiration, ${ }^{17}$ and Inward-attention meditation practice appears to push the sympathovagal balance to parasympathetic predominance and induce regular oscillations in heart rate. ${ }^{18}$ Additional studies were based on heart rate variabilities of different levels of Zen meditation. ${ }^{19}$

The current study investigated the potential health benefits associated with Zen meditation training. The religious training in meditation that Zen monks experience is extremely challenging. This rigorousness leads some monks to abandon their training and others to develop physical and mental illnesses. Trainees who remain in the monastery typically spend hours in meditation each day in order to enhance their concentration abilities. ${ }^{20}$ Despite recent scientific interest in MBSR; no studies have yet been published on health-related quality of life (HRQOL) and psychologic distress among Zen monk trainees. This study addresses this empirical gap by focusing on the HRQOL and mental health among trainees at Japanese Rinzai Zen training centers.

There are two major Zen sects in Japan, Rinzai, and Soto. The basic stance of the Rinzai is self-realization, which is regarded as the essence of Shakyamuni's (the historical Buddha) teaching. Using a Zen questionnaire (koan) for meditation is one of the important features of the Rinzai sect. Koan aids in understanding stories that surpass intellectual understanding. To obtain major psychologic ("sense of oneness") as well as physiologic effects, Zen practitioners cultivate particular skills, such as slow breathing. Breathing control is given more emphasis among the Rinzai Zen practitioners. Their discipline often involves training in very slow and quiet breathing and chanting and attention to the sensations accompanying respiration. ${ }^{21}$

It was hypothesized that experiences with Zen Buddhism training would improve HRQOL and mental health as measured by the International Quality of Life Assessment Short Form-36, version 2 (SF-36), and the General Health Questionnaire (GHQ-28).

\section{Materials and Methods}

\section{Procedure}

This study was approved by the Human Subjects Institutional Review Board of Iwate National Hospital, Na- tional Hospital Organization. The head office directors of the largest branch of the Rinzai Zen religion were invited to participate in the survey. Zen monasteries are generally very conservative and would not normally allow the mental status of their trainees to be examined. However, in this particular case, the directors were cooperative because the first author of this article had participated in Rinzai Zen training at the headquarters monastery. Twenty Zen monasteries were selected. Of them, 13 directors agreed to participate. Questionnaires containing age, gender, monastery addition day, past and present illness history, and Japanese versions of the SF-36 and GHQ-28 were disseminated to the individual trainees by the leaders at the various monasteries. All the participants who did not agree to participate in this study were excluded. All 462 registered monk trainees at 13 monasteries were included in this study. The purpose and contents of the questionnaires were explained to the trainees by the leaders before their voluntary participation. The trainees were asked to complete the questionnaires and return them, along with their written informed consent, in a sealed envelope to their leader. A total of 294 questionnaires from 13 monasteries were received. A total of 256 questionnaires were obtained with the informed consent, and 198 questionnaires completed all answers. Trainees ranged in age from 22 to 63 years (mean $=27.7$, standard deviation $[\mathrm{SD}]=6.5)$. The mean training length was 2.6 years $(\mathrm{SD}=3.2)$. All of the trainees were men.

\section{Instruments and measures}

SF-36. The SF-36 is a 36-item survey that assesses HRQOL. The SF-36 questionnaire was translated into Japanese and validated by Fukuhara et al. ${ }^{22-24}$ The instrument is widely used in the evaluation of allopathic treatment modalities and has been used in many Japanese studies. Permission was obtained for using questionnaire version 2 in this study from the Medical Outcomes Trust, Health Assessment Lab, and Quality Metric Incorporated, as well as from Shunichi Fukuhara Scores. Eight health concepts are calculated: Physical Functioning (PF), Role Physical (RP), Bodily Pain (BP), General Health (GH), Vitality (VT), Social Functioning (SF), Role Emotional (RE), and Mental Health $(\mathrm{MH})$. The first four concepts assess the physical aspects of HRQOL and result in a Physical Component Summary (PCS). The next four assess the mental or psychosocial aspects of HRQOL and result in a Mental Component Summary (MCS). The scoring was based on Japanese standards, and the subscale scores ranged from 0 to 100; higher scores indicated better quality of life. ${ }^{24}$ This scoring system was used for this study and calculated Japanese norm-based subscale, PCS, and MCS scores by using SF-36 version 2 scoring program provided from Institute for Health Outcome \& Process Evaluation research. The system is written in the SF-36 manual. ${ }^{24}$

GHQ-28. The GHQ is a self-administered tool originally developed for the screening of nonpsychotic psychiatric illness. It is used in both clinical settings and epidemiologic studies to investigate the mental health of general populations. The GHQ was designed to provide a general measure of mental health and psychologic distress levels by measuring the presence and levels of distressing symptoms and the 
Table 1. SF-36 Scores Among Groups I, II, ANd III

\begin{tabular}{|c|c|c|c|c|c|c|}
\hline & & & $\begin{array}{c}\text { Group } I(<1 \text { year }) \\
\quad(\mathrm{n}=57)\end{array}$ & $\begin{array}{c}\text { Group II (1-3 years }) \\
(\mathrm{n}=81)\end{array}$ & $\begin{array}{c}\text { Group III }(\geq 3 \text { years }) \\
(\mathrm{n}=60)\end{array}$ & $\mathrm{p}$-Value \\
\hline Age (years) & & & $28.1 \pm 9.2$ & $25.8 \pm 3.1$ & $29.9 \pm 6.2$ & \\
\hline \multirow[t]{10}{*}{ SF-36 } & PCS & & $53.7 \pm 10.1$ & $55.8 \pm 8.2$ & $57.2 \pm 7.3$ & 0.085 \\
\hline & MCS & & $41.7 \pm 9.7$ & $43.3 \pm 10.4$ & $47.0 \pm 9.8$ & $0.012^{*}$ \\
\hline & & PF & $91.0 \pm 12.5$ & $95.1 \pm 7.2$ & $97.2 \pm 5.2$ & $0.001^{\mathrm{a}}$ \\
\hline & & $\mathrm{RP}$ & $79.7 \pm 18.8$ & $86.6 \pm 18.6$ & $91.8 \pm 12.7$ & $0.001^{\mathrm{a}}$ \\
\hline & & $\mathrm{BP}$ & $62.0 \pm 24.3$ & $69.2 \pm 24.3$ & $74.9 \pm 24.9$ & $0.015^{\mathrm{a}}$ \\
\hline & & $\mathrm{GH}$ & $55.7 \pm 17.2$ & $59.4 \pm 19.9$ & $68.1 \pm 16.3$ & $0.003^{\mathrm{a}}$ \\
\hline & & VT & $47.3 \pm 18.1$ & $51.1 \pm 22.4$ & $58.1 \pm 16.9$ & $0.009^{\mathrm{a}}$ \\
\hline & & SF & $67.8 \pm 29.3$ & $72.2 \pm 31.6$ & $79.0 \pm 29.1$ & 0.074 \\
\hline & & RE & $76.6 \pm 25.5$ & $84.4 \pm 19.4$ & $90.8 \pm 13.7$ & $0.005^{\mathrm{a}}$ \\
\hline & & $\mathrm{MH}$ & $55.3 \pm 20.0$ & $62.2 \pm 19.6$ & $68.3 \pm 15.5$ & $0.003^{\mathrm{a}}$ \\
\hline
\end{tabular}

PCS and MCS, one-way analysis of variance. Subscales: Kruskal-Wallis test.

*Significant difference between group I and group II at Tukey test.

a Significant difference.

SF-36, International Quality of Life Assessment Short Form-36; PCS, Physical Component Summary; MCS, Mental Component Summary; PF, Physical Functioning; RP, Role Physical; BP, Bodily Pain; GH, General Health; VT, Vitality; SF, Social Functioning; RE, Role Emotional; $\mathrm{MH}$, Mental Health.

individual's inability to carry out normal functions. Each item includes four answer options scored from 0 to 3, for a total score ranged from 0 to 84 , or by an alternative binary method in which a threshold of 4 was set for "caseness" (or the presence of psychiatric distress). The GHQ includes "positive" items that represent an ability to carry out normal functions (e.g., "Have you recently been able to enjoy your normal dayto-day activities?"), and "negative" items that address distressing symptoms (e.g., "Have you recently felt constantly under strain?"). A person with a high GHQ score was considered to have a high level of psychologic distress, including symptoms of somatization, anxiety, social dysfunction, and depression. $^{25}$ In addition, the total score was standardized including normal and neurosis. The 28-item GHQ-28 was considered the criterion standard of questionnaires for screening psychiatric disorders in the general population and nonpsychiatric patients. ${ }^{26}$ The Japanese version of the instrument has been previously validated, ${ }^{25,27,28}$ and many GHQ studies have recently been conducted in Japan. ${ }^{29}$

\section{Analysis}

First, the study participants were divided according to how long they had been in training: group I ( $<1$ year), group II ( $\geq 1$ year and <3years), and group III ( $\geq 3$ years).
The eight SF-36 subscale scores (both raw and norm-based), PCS, and MCS scores were calculated. HRQOL is affected by many factors based on cultural differences, so the norm-based score is necessary to understand the results. ${ }^{24}$ Norm-based scores were used rather than non-norm-based scores.

Total GHQ-28 scores were calculated, as well as subscale scores for somatization, anxiety, social dysfunction, and depression.

The authors considered whether the data were normally distributed. Normally distributed data were analyzed by a one-way analysis of variance and Tukey test for multiple comparisons by using IBM SPSS Statistics ver. 21. Nondistributed data were analyzed by a Kruskal-Wallis test. The significance level was set at 95\% confidence interval.

\section{Results}

The mean age of study participants was $27.7(\mathrm{SD}=6.5)$ years, all participants were male, and the mean training length was $2.6(\mathrm{SD}=3.2)$ years.

Table 1 shows the SF-36 subscale scores, PCS, and MSC scores. The SF-36 subscales were non-normally distributed. The SF-36 PCS and MCS were normally distributed.

The SF-36 seven subscale scores (PF, RP, BP, GH, VT, RE, and $\mathrm{MH})$ were statistically significant $(p=0.001,0.001,0.015$,

Table 2. General Health Questionnaire Scores and Ages

\begin{tabular}{|c|c|c|c|c|c|}
\hline & & $\begin{array}{c}\text { Group } I(<1 \text { year }) \\
\quad(\mathrm{n}=57)\end{array}$ & $\begin{array}{l}\text { Group II (1-3 years) } \\
(\mathrm{n}=81)\end{array}$ & $\begin{array}{c}\text { Group III }(\geq 3 \text { years }) \\
(\mathrm{n}=60)\end{array}$ & ${ }^{*} \mathrm{p}-$ Value \\
\hline Age (years) & & $28.1 \pm 9.2$ & $25.8 \pm 3.1$ & $29.9 \pm 6.2$ & \\
\hline \multirow[t]{5}{*}{ GHQ } & Total & $10.7 \pm 6.8$ & $8.7 \pm 6.5$ & $5.3 \pm 5.2$ & $<0.001$ \\
\hline & Somatization & $3.4 \pm 2.4$ & $2.9 \pm 2.1$ & $1.9 \pm 2.1$ & 0.001 \\
\hline & Anxiety & $3.5 \pm 2.1$ & $2.7 \pm 2.2$ & $2.0 \pm 2.0$ & $<0.001$ \\
\hline & Social Dysfunction & $2.4 \pm 2.1$ & $1.6 \pm 1.8$ & $1.0 \pm 1.4$ & $<0.001$ \\
\hline & Depression & $1.5 \pm 2.2$ & $1.5 \pm 2.0$ & $0.5 \pm 1.2$ & $<0.001$ \\
\hline
\end{tabular}

*Kruskal-Wallis test.

General Health Questionnaire (GHQ) total and all subscale scores showed significant difference. 
$0.003,0.009,0.005,0.003$, respectively) by using the KruskalWallis test.

The SF-36 MCS score were also significantly different $(p<0.05)$ between the groups. The scores between group I ( $<1$ year) and group III ( $\geq 3$ years) were statistically different $(p=0.012)$. The SF-36 PCS scores between groups did not attain statistical significance $(p=0.085)$.

Table 2 shows the GHQ-28 total and subscales (somatization, anxiety, social dysfunction, and depression) scores that were not normally distributed. All of these scores were significantly different ( $p$ values of total, anxiety, social dysfunction, and depression were $<0.001, p$ value of somatization was 0.001) between the groups.

\section{Discussion}

It was hypothesized that Zen training would lead to improved HRQOL and lower psychologic distress, as measured by the SF-36 and GHQ-28. For the SF-36, scores on all of subscales were lower than Japanese standards for participants who had trained for a shorter length of time, and scores on all of the subscales, except SF, were increased for participants who had trained for longer periods. Since Zen training practices are organized and regular, the trainees may have become accustomed to the physical rigors. Modern young people may find Zen monastery training to be very strict, rigid, and distressing, especially since it leaves little free time, limits contact with those outside the monastery, and requires adaptation to a different lifestyle. The closed environment of Zen monasteries would affect the finding of no significant difference in the SF-36 PCS and SF scores. In addition, the vertical relationship between young trainees and senior trainees or supervisors may be a cause of distress because senior supervisors coach sharply and strictly. It is also speculated that the motivations to enter the monasteries were diverse among the participants in this study. Some people may enter training against their will, while others are attracted to the religious teachings. Sometimes Zen trainees join monasteries in order to become successors in the Zen temples run by their monk fathers. After 1-3 years of training, they can be certified as a monk but not as a higher level of monk. Many monk trainees quit their training after $1-3$ years. The backgrounds of the participants stated above would reduce the SF-36 scores of trainees with shorter length training, whereas longer periods of Zen training would improve their SF-36 scores.

According to previous studies, the mean total score for the Japanese GHQ-28 is $7.73(\mathrm{SD}=6.19)$ and the mean total score for neurosis is $13.93(\mathrm{SD}=6.51) \cdot{ }^{25,27,28}$ The data of this current study show that GHQ-28 total scores of group I ( $<1$ year) were higher than the Japanese mean total scores, while the GHQ-28 total scores of group III ( $\geq 3$ years) were lower than the Japanese mean total scores. These findings suggest that monks who trained for a shorter length of time had difficulty coping because of their tough training experience. However, the GHQ-28 total scores and scores for each of the subscales decreased with longer length of training. This finding suggests that longer Zen training may have been influential in improving the respondents' general mental health. It is important to note, however, that Zen training is designed to focus on the internal experience of the trainees, and the items on the GHQ-28 may not capture all of the changes that trainees experience.
Previous research using the SF-36 and GHQ-28 has examined the effectiveness of a psychoeducational intervention program and has reported that the positive effects of the intervention lasted beyond the duration of the program. ${ }^{30}$ Zen training may be considered a similar type of intervention program, in which trainees learn from seniors and supervisors. It is to be expected that systematic Zen training, like other forms of training, would continue to have positive effects beyond the end of the training program.

This study had several important limitations. All assessment measures were self-reported psychologic questionnaires, which are inherently limited and open to response bias. The validity of the GHQ-28 as a screening tool is especially limited in patients with more chronic symptoms and those with more frequent social and interpersonal problems. ${ }^{31}$ It may be possible that due to shorter periods involved in training, trainees may not adapt to the Zen lifestyle and feel anxious about the strict practices and systems. Trainees who were unable to adapt to the lifestyle may quit their training at an earlier stage. However, some monasteries are unwilling to acknowledge the number of trainees who have quit the practice.

This traditional system has been continued in a closed world for a long time. This study is the first step to understand the still-closed traditional Zen monasteries.

The way of life in Zen monasteries is unknown and very mysterious to most people, despite the fact that these traditions and customs have been practiced for several hundred years. Indeed, the trainee's level of distress is connected to individual factors. As noted earlier, MBSR is based in part on Zen Buddhist teachings. More research is necessary to understand the effects of Zen training and the potential medical benefits. This study utilized a cross-sectional method, but longitudinal studies will be necessary to thoroughly understand the effects of Zen Buddhist training.

There are no previous systematic studies of HRQOL and psychologic distress among Japanese Zen trainees, despite several hundred years of Japanese Zen history. This study provides a point of departure for scientists to cooperate with Buddhists in the hopes that this type of work may develop new findings and create a healthier world. ${ }^{32}$ Future studies should explore other Zen Buddhist practices in addition to meditation, such as food customs, insight practices, and beliefs about human relationships, because these techniques may provide effective remedies for our busy and complicated modern social lives. Since Zen training changes the individual's inward status, qualitative studies (for example, utilizing individual interviews) may also aid in understanding the mental health of Zen Buddhist trainees.

\section{Conclusions}

It is concluded that longer Zen training may improve the trainee's QOL and GHQ. A more detailed qualitative and longitudinal study is required in order to fully understand and assess the relationship between Zen training and QOL and GHQ suggested by this study.

\section{Acknowledgments}

We thank the Rinzai Zen monk trainees, training leaders, and the Rinzai Zen temples (Myoshinji temple complex, Kyoto) head office. 


\section{Authors' Contributions}

All the authors contributed to and have approved the final manuscript. FS was the project leader for the study, responsible for the data collection and the first draft of the manuscript. MT contributed the statistical analyses. HG contributed to the data collection and statistical analyses. DSA was responsible for the overall design of the study.

\section{Disclosure Statement}

No competing financial interests exist.

\section{References}

1. Kabat-Zinn J, Lipworth L, Burney R. The clinical use of mindfulness meditation for the self-regulation of chronic pain. J Behav Med 1985;8:163-190.

2. Reibel DK, Greeson JM, Brainard GC, et al. Mindfulnessbased stress reduction and health-related quality of life in a heterogeneous patient population. Gen Hosp Psychiatry 2001;23:183-192.

3. Sudsuang R, Chentanez V, Veluvan K. Effect of Buddhist meditation on serum cortisol and total protein levels, blood pressure, pulse rate, lung volume and reaction time. Physiol Behav 1991;50:543-548.

4. Wenneberg SR, Schneider RH, Walton KG. A controlled study of the effects of the Transcendental Meditation program on cardiovascular reactivity and ambulatory blood pressure. Int J Neurosci 1997;89:15-28.

5. Shapiro SL, Schwartz GE, Bonner G. Effects of mindfulnessbased stress reduction on medical and premedical students. I Behav Med 1998;21:581-599.

6. Davidson RJ, Kabat-Zinn J, Schumacher J, et al. Alterations in brain and immune function produced by mindfulness meditation. Psychosom Med 2003;65:564-570.

7. Davidson RJ, Kabat-Zinn J, Schumacher J, et al. Alterations in brain and immune function produced by mindfulness meditation. Psychosom Med 2003;65:564-570.

8. Lazar SW, Kerr CE, Wasserman RH. Meditation experience is associated with increased cortical thickness. Neuroreport 2005;16:1893-1897.

9. Tang YY, Ma Y, Wang J, et al. Short-term meditation training improves attention and self-regulation. Proc Natl Acad Sci U S A 2007;104:17152-17156.

10. Liu CY, Wei CC, Lo PC. Variation Analysis of sphygmogram to assess cardiovascular system under meditation. Evid Based Complement Alternat Med 2009;6:107-112.

11. Astin JA. Stress reduction through mindfulness meditation: Effects on psychological symptomatology, sense of control, and spiritual experiences. Psychother Psychosom 1997;66: 97-106.

12. Praissman S. Mindfulness-based stress reduction: A literature review and clinician's guide. J Am Acad Nurse Pract 2008;20:212-216.

13. Nishitani K. Religion and Nothingness. Berkley, CA: University of California Press, 1982.

14. Kit W. The Complete Book of Zen Training. Boston: Tuttle Publishing, 2001.

15. Chiesa A. Zen meditation: An integration of current evidence. J Altern Complement Med 2009;15:585-592.
16. Ospina MB, Bond $\mathrm{K}$, Karkhaneh M, et al. Meditation practices for health: State of the research. Evid Rep Technol Assess (Full Rep) 2007;155:1-263.

17. Cysarz D, Büssing A. Cardiorespiratory synchronization during Zen meditation. Eur J Appl Physiol 2005;95:88-95.

18. $\mathrm{Wu}$ SD, Lo PC. Inward-attention meditation increases parasympathetic activity: A study based on heart rate variability. Biomed Res 2008;29:245-250.

19. Peressutti C, Martín-González JM, M García-Manso J, Mesa D. Heart rate dynamics in different levels of Zen meditation. Int J Cardiol 2010;145:142-146.

20. Knight J. Religion and science: Buddhism on the brain. Nature 2004;432:670.

21. Lehrer P, Sasaki Y, Saito Y. Zazen and cardiac variability. Psychosom Med 1999;61:812-821.

22. Fukuhara S, Bito S, Green J, et al. Translation, adaptation, and validation of the SF-36 Health Survey for use in Japan. J Clin Epidemiol 1998;51:1037-1044.

23. Fukuhara S, Ware JE Jr, Kosinski M, et al. Psychometric and clinical tests of validity of the Japanese SF-36 Health Survey. I Clin Epidemiol 1998;51:1045-1053.

24. Fukuhara S, Suzukamo Y. Manual of SF-36v 2 Japanese Version. Kyoto: Institute for Health Outcomes \& Process Evaluation Research, 2004.

25. Goldverg DP. A Users' Guide to the General Health Questionnaire. Windsor: NFER-Nelson, 1988.

26. de la Revilla Ahumada L, de los Ríos Alvarez AM, Luna del Castillo JD. Use of the Goldberg General Health Questionnaire (GHQ-28) to detect psychosocial problems in the family physician's office. Aten Primaria 2004;33:417-422; discussion 423-425 (in Spanish).

27. Nakagawa YI. Japanese Version of the General Health Questionnaire. Tokyo: Nihon Bunka Kagakusha, 1985.

28. Iwata N, Uno B, Suzuki T. Psychometric properties of the 30item version general health questionnaire in Japanese. Jpn J Psychiatry Neurol 1994;48:547-556.

29. Hayasaka Y, Nakamura K, Yamamoto M, et al. Work environment and mental health status assessed by the general health questionnaire in female Japanese doctors. Ind Health 2007;45:781-786.

30. Martín-Carrasco M, Martín MF, Valero CP, et al. Effectiveness of a psychoeducational intervention program in the reduction of caregiver burden in Alzheimer's disease patients' caregivers. Int J Geriatr Psychiatry 2009;24:489-499.

31. Benjamin S, Decalmer P, Haran D. Community screening for mental illness: A validity study of the General Health Questionnaire. Br J Psychiatry 1982;140:174-180.

32. Barinaga M. Buddhism and neuroscience: Studying the welltrained mind. Science 2003;302:44-46.

Address correspondence to: Fumio Shaku, MD

Department of General Medicine University of Tsukuba

1-1-1 Tennodai, Tsukuba Ibaraki 3058575 Japan

E-mail: shaku@md.tsukuba.ac.jp 
This article has been cited by:

1. Meghan Wood, Hayden Center, Stacy C. Parenteau. 2016. Social media addiction and psychological adjustment: religiosity and spirituality in the age of social media. Mental Health, Religion \& Culture 19:9, 972-983. [Crossref]

2. Marta Alda, Marta Puebla-Guedea, Baltasar Rodero, Marcelo Demarzo, Jesus Montero-Marin, Miquel Roca, Javier GarciaCampayo. 2016. Zen meditation, Length of Telomeres, and the Role of Experiential Avoidance and Compassion. Mindfulness 7:3, 651-659. [Crossref]

3. Kenji Fujitani, Matt Carroll, Robert Yanagisawa, Craig Katz. 2016. Burnout and Psychiatric Distress in Local Caregivers Two Years After the 2011 Great East Japan Earthquake and Fukushima Nuclear Radiation Disaster. Community Mental Health Journal 52:1, 39-45. [Crossref] 